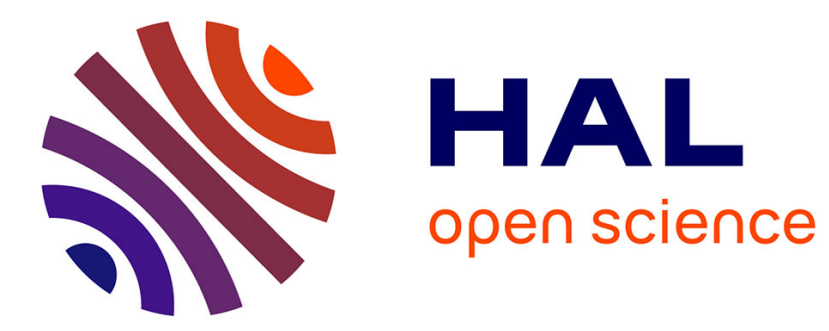

\title{
Solid polymer electrolytes from copolymers based on vinyl dimethyl phosphonate and vinylidene fluoride
}

\author{
Lu Bai, Mohammad Webhi, Guillaume Dolphijn, Bruno Ameduri,
} Jean-François Gohy

\section{- To cite this version:}

Lu Bai, Mohammad Webhi, Guillaume Dolphijn, Bruno Ameduri, Jean-François Gohy. Solid polymer electrolytes from copolymers based on vinyl dimethyl phosphonate and vinylidene fluoride. Macromolecular Chemistry and Physics, 2021, 222 (1), pp.2000389. 10.1002/macp.202000389 . hal03143151

\author{
HAL Id: hal-03143151 \\ https://hal.science/hal-03143151
}

Submitted on 16 Feb 2021

HAL is a multi-disciplinary open access archive for the deposit and dissemination of scientific research documents, whether they are published or not. The documents may come from teaching and research institutions in France or abroad, or from public or private research centers.
L'archive ouverte pluridisciplinaire HAL, est destinée au dépôt et à la diffusion de documents scientifiques de niveau recherche, publiés ou non, émanant des établissements d'enseignement et de recherche français ou étrangers, des laboratoires publics ou privés. 


\section{Solid polymer electrolytes from copolymers based on vinyl dimethyl phosphonate and vinylidene fluoride}

Received 00th January 20xx, Accepted 00th January 20xx DOI: $10.1039 / \times 0 \times x 00000 x$

\author{
Lu Bai, ${ }^{\text {a\$ }}$ Mohammad Webhi, ${ }^{\text {b\$ }}$ Guillaume Dolphijn, ${ }^{a}$ Bruno Améduri, ${ }^{\text {b* }}$ Jean-François Gohy ${ }^{a^{*}}$
}

\section{Introduction}

The invention of the Li-ion battery is regarded as one of the most important achievement in the field of rechargeable batteries, due to its huge impact on the evolution of the human society and how it changed the routine of people's dayto-day life, by opening the door to new technological advancements such as modern smartphones, laptops, portable power tools and electric vehicles. ${ }^{1-3}$ These batteries are usually composed of the anode, the cathode, an electrolyte and the separator. ${ }^{4}$ The electrolyte is a material that plays the role of transporting the Li-ions from the cathode to the anode during charging and in reverse during a discharge. ${ }^{5}$ Such a material to be efficiently used as electrolytes in Li-ion batteries should have specific features such as a high ionic conductivity and excellent chemical, thermal and electrochemical stabilities. ${ }^{5}$ Liquid electrolytes based on lithium salts dissolved in organic solvents are essentially used in nowadays batteries since they display excellent ionic conductivity but suffers from limited chemical, thermal and electrochemical stabilities causing fire hazards. ${ }^{5}$ Moreover, liquid electrolytes require the use of a separator in the battery assembly to prevent contacts between the anode and the cathode. Those limitations can be overcome by using polymers as electrolytes. In this context, various

\footnotetext{
a. Institute of Condensed Matter and Nanosciences (IMCN), Université catholique de Louvain, Place L. Pasteur 1, 1348 Louvain-la-Neuve, Belgium.

Email: jean-francois.gohy@uclouvain.be

${ }^{b}$ Institut Charles Gerhardt CNRS, ENSCM, UM, Montpellier, France.

E-mail: bruno.ameduri@enscm.fr

Electronic Supplementary Information (ESI) available: ${ }^{1} \mathrm{H},{ }^{19} \mathrm{~F}$, and ${ }^{31} \mathrm{P}$ NMR spectra of the synthesized copolymers, ionic conductivity values at different temperatures for the investigated SPEs. See DOI: 10.1039/x0xx00000x

${ }^{\$}$ Both authors equally contributed to this work.
}

polymers have been studied for their potential application as electrolytes in Li-ion batteries, such as poly(ethylene oxide) (PEO), ${ }^{6}$ poly(acrylonitrile) (PAN), ${ }^{7}$ poly (methyl methacrylate) $(\mathrm{PMMA})^{8}$ and poly(vinylidene fluoride) (PVDF), ${ }^{9}$ among others. ${ }^{10}$ Polymers can be used either for gel polymer electrolytes (GPEs) when they are swollen with liquid electrolytes or as solid polymer electrolytes (SPEs) when they are simply mixed with lithium salts. The most promising candidates for the next generation batteries are SPEs since they display excellent chemical, thermal and electrochemical stabilities allowing their utilization with high voltage cathode materials and in new technologies such as lithium metal batteries. ${ }^{10}$ Moreover, they generally show excellent mechanical properties and do not require any separator. However, SPEs, due to their solid nature, are characterized by low ionic conductivity at room temperature. ${ }^{10}$

Among the different polymers used for the preparation of GPEs and SPEs, PVDF has reached momentum because of its outstanding properties. PVDF is the second largest produced fluorinated polymer due to its outstanding properties that it gains from the small size and electronegative nature of its fluorine atoms. Such characteristics led PVDF-based materials to find applications in a wide range of fields. ${ }^{11-15}$ In addition to that, copolymers of VDF have been extensively studied for their potential application in GPEs and SPEs due to their outstanding mechanical properties and electrochemical stability. Liu et. al reported the preparation of polyethylene supported PVDF-cellulose acetate butyrate blended polymer electrolyte for lithium ion batteries. ${ }^{9}$ The obtained blends show satisfactory performances, however, the poor ionic conductivity deemed this polymer blend unsuitable for battery applications. They later on modified this electrolyte blend by 
doping with $\mathrm{SiO}_{2}$ nanoparticles which led to an improvement in the ionic conductivity from 1.16 to $2.98 \mathrm{~ms} \mathrm{~cm}^{-1}$. ${ }^{16}$ On the other hand, poly(vinylidene fluoride-co-hexafluoropropylene) (PVDF-HFP) composite polymer electrolytes, prepared via phase inversion technique, have drawn some attention due to their high dielectric constant $(\varepsilon=8.4)$ which facilitates the solvent free dissolving of the Li salts in the bulk polymer. ${ }^{17} \mathrm{Xie}$ et. al studied the effect of doping PVDF-HFP copolymer composites with fumed alumina and reported ionic conductivity values as high as $0.89 \mathrm{~ms} \mathrm{~cm}{ }^{-1} .{ }^{18}$ However, a better ionic conductivity was obtained by Chen et al. who prepared a flexible lithium ion battery based on PVDF-HFP codoped with poly(ethylene oxide) and graphene oxide electrolyte, leading to an ionic conductivity of $2.1 \mathrm{mS} \mathrm{cm}^{-1}$ and capacity retention of $92 \%$ after 2000 cycles. ${ }^{19}$

Following a different approach, our team focused on the preparation of PVDF based GPEs by mixing copolymers of VDF and functional trifluoromethacrylate esters (MAF-esters) with lithium salts and ionic liquids. ${ }^{20,21}$ The first generation of GPEs based on poly[VDF-co-MAF-oligo(EO)] copolymers, prepared from the copolymerization of VDF and triethylene glycol functional MAF ester [MAF-oligo(EO)], showed ionic conductivities of $0.2 \mathrm{mS} \mathrm{cm}^{-1}$ at ambient temperature and was electrochemically stable throughout a wide range of potentials. $^{20}$ In the second generation of those GPEs, the substitution of the MAF-oligo(EO) ester by a perfluoroalkyl ether functional one (MAF-PFE), to obtain poly(VDF-co-MAFPFE) copolymers, ${ }^{21}$ led to a significant increase in the ionic conductivity reaching up to $3 \mathrm{mS} \mathrm{cm} \mathrm{cm}^{-1}$ at room temperature. Finally, solvent-free SPEs were also investigated, prepared from a cyclic carbonate functional MAF (MAF-cyCB) and VDF. The SPEs were obtained by mixing the resulting poly(VDF-coMAF-cyCB) copolymers with various amounts of $\mathrm{LiClO}_{4}$ and showed excellent ionic conductivity values as high as $0.2 \mathrm{mS}$ $\mathrm{cm}^{-1}$ at room temperature and high transference numbers for $\mathrm{Li}^{+}$ions (ca. 0.7) $)^{22}$ and were much higher than those observed at room temperature for classical PEO-based SPEs.

Just a while ago, our team studied the potential application of phosphonate functional fluorinated polymers for selective extraction of rare earth metals ${ }^{23}$ or lanthanides from aqueous media. ${ }^{24}$ The rising interest in phosphorus compounds is due to their interesting properties such as high acidity, ${ }^{25}$ anticorrosion, ${ }^{26}$ adhesion, ${ }^{27}$ flame retardancy, ${ }^{28}$ proton exchange membranes, ${ }^{29-33}$ biomedical applications ${ }^{34}$ and complex formation. ${ }^{35}$ To the best of our knowledge, there is no phosphorus functional fluoropolymer that has been employed as an electrolyte in Li-ion batteries, ${ }^{36}$ thus it is worth investigating the combination of the fluorine and phosphorus atoms, which bring synergistic complementary properties, for the preparation of new electrolytes for Li-ion batteries.

Towards this direction, the present work aims at assessing how functional fluorophosphorus copolymers behave as solid polymer electrolytes. First, copolymers based on vinyl dimethyl phosphonate (VDMP), reported as a poorly reactive monomer $^{37}$ that fails to homopolymerize, ${ }^{38}$ and vinylidene fluoride (VDF), will be synthesized and characterized. Secondly, these copolymers will be mixed with lithium bis(trifluoromethanesulfonyl)imide) (LiTFSI) to prepare original SPEs. The ionic conductivity of the accordingly obtained SPES will be determined as a function of temperature, as well their electrochemical stability. Finally, some preliminary flammability tests will be conducted in order to assess the fireresistance properties of the prepared SPEs.

\section{Experimental section}

\section{Materials}

All reagents were used as received unless stated otherwise. Vinylidene fluoride (1,1-difluoroethylene, VDF) was kindly given by Arkema (Pierre Bénite, France). 2,5-dimethyl-2,5di(tert-butylperoxy) hexane (DTBPH, purity 90\%, Trigonox ${ }^{\circledR}$ 101) and vinyl dimethylphosphonate (VDMP, purity 90\%) were bought from Akzo Nobel (Chalons sur Marne, France) and $A B C R$ (Karlsruhe, Germany), respectively. Pentane and dimethyl carbonate (DMC, purity $>99 \%$ ) were purchased from Sigma-Aldrich. The NMR spectroscopy solvent, deuterated dimethyl sulfoxide (DMSO- $d_{6}$ ), was obtained from Eurisotop (Grenoble, France) (purity $>99.8 \%$ ) while Lithium bis(trifluoromethanesulfonyl)imide) (LiTFSI) from Solvay.

\section{Copolymerisation of vinylidene fluoride (VDF) and vinyl dimethylphosphonate (VDMP)}

Radical copolymerization reactions of VDMP with VDF were carried out as reported in our recent publications. ${ }^{23,24}$ The reactions were achieved out in a $50 \mathrm{~mL}$ Hastelloy autoclave Parr system (HC 276), equipped with a mechanical Hastelloy anchor, a manometer, inlet and outlet valves, a rupture disk (3000 PSI), and an electronic controller. Prior starting the reaction, a solution composed of DTBPH $(0.601 \mathrm{~g}, 2.08 \mathrm{mmol})$, and VDMP $(2.90 \mathrm{~g}, 20.82 \mathrm{mmol})$ dissolved in dimethyl carbonate (DMC, $30 \mathrm{~mL}$ ) was degassed under $\mathrm{N}_{2}$ bubbling for $30 \mathrm{~min}$. In the meantime, the autoclave was inspected for any possible leaks by setting it up under 30 bar-nitrogen, then placed under vacuum ( $40 \times 10^{-6}$ bar) for $30 \mathrm{~min}$ to avoid any oxygen. From a funnel tightly connected to its introduction valve, the above solution was introduced into the autoclave. The reactor was then cooled, and VDF gas was transferred (its amount was monitored on a balance by difference of weight). The reactor was then allowed to warm up to room temperature and heated to $115{ }^{\circ} \mathrm{C}$, (for which the half-life of the initiator is $10 \mathrm{~h}$ ). The max pressure reached at this temperature was $P_{\max }=33$ bar. Both temperature and pressure were recorded and the reaction was stopped when no more drop of pressure was observed $\left(P_{\min }=9\right.$ bar $)$ after 16 $\mathrm{h}$. Then, the autoclave was placed in an ice bath to allow the unreacted gaseous VDF to vent off. The total product mixture was transferred from the autoclave into a round bottom flask where the solvent and unreacted liquid VDMP comonomer were completely removed under vacuum. The resulting crude product was then dissolved in dry acetone and precipitated from chilled pentane, filtered and finally dried under vacuum $\left(20 \times 10^{-3}\right.$ bar, $\left.50^{\circ} \mathrm{C}\right)$ for $24 \mathrm{~h}$. The obtained copolymers, as off- 
white solids (P1 and P2) or viscous amorphous wax (P3), were characterized by ${ }^{19} \mathrm{~F},{ }^{1} \mathrm{H}$, and ${ }^{31} \mathrm{P}$ NMR spectroscopies.

${ }^{19} \mathrm{~F}$ NMR $\left(376 \mathrm{MHz}\right.$, DMSO- $d_{6}, \delta \mathrm{ppm}$ of P1, Table 1 , Figure S2): -91.5 to $-93.5\left(-\mathrm{CH}_{2} \mathrm{CF}_{2}-\mathrm{CH}_{2} \mathrm{CF}_{2}\right.$-normal VDF-VDF H-T dyad addition); -94.7 ( $-\mathrm{CF}_{2}$ of VDF in the VDF-VDMP dyad); -114 ( $-\mathrm{CH}_{2} \mathrm{CF}_{2}-\mathrm{CF}_{2} \mathrm{CH}_{2}-\mathrm{CH}_{2}$, reverse VDF-VDF $\mathrm{H}-\mathrm{H}$ dyad addition); $114.5\left(\mathrm{dtt},{ }^{2} J_{\mathrm{HF}}=55.0 \mathrm{~Hz},{ }^{3} J_{\mathrm{HF}}=16.0 \mathrm{~Hz}\right.$ and ${ }^{4} J_{\mathrm{FF}}=6 \mathrm{~Hz}, \mathrm{CF}_{2^{-}}$ $\mathrm{CH}_{2} \mathrm{CF}_{2}-\mathrm{H}$, chain-end from transfer); -116.2 ( $-\mathrm{CH}_{2} \mathrm{CF}_{2}-\mathrm{CF}_{2} \mathrm{CH}_{2}-\mathrm{CH}_{2}$, reverse VDF-VDF H-H dyad addition).

${ }^{1} \mathrm{H}$ NMR (400 MHz, DMSO- $d_{6}, \delta$ ppm of P1, Table 1 , Figure S1): 1.6 to $1.9\left[\mathrm{~m}, 1 \mathrm{H}-\mathrm{CF}_{2} \mathrm{CH}_{2}-\mathrm{CH}_{2} \mathrm{CH}-\mathrm{PO}\left(\mathrm{OCH}_{3}\right)_{2}\right], 2.15$ to $2.40(\mathrm{~m}$, $-\mathrm{CF}_{2} \mathrm{CH}_{2}-\mathrm{CH}_{2} \mathrm{CF}_{2}-$ reverse VDF-VDF T-T dyad addition); 2.60 to $3.20\left(\mathrm{~m},-\mathrm{CH}_{2} \mathrm{CF}_{2}-\mathrm{CH}_{2} \mathrm{CF}_{2}-\right.$, normal VDF-VDF $\mathrm{H}-\mathrm{T}$ dyad addition), $2.80 \quad\left(-\mathrm{CH}_{2} \mathrm{CH}-\left(\mathrm{PO}\left(\mathrm{OCH}_{3}\right)_{2}\right)\right) ; 3.6[\mathrm{~s}, 6 \mathrm{H}$, $-\mathrm{CF}_{2} \mathrm{CH}_{2}-\mathrm{CH}_{2} \mathrm{CH}-\mathrm{PO}\left(\mathrm{OCH}_{3}\right)_{2}$ ]; 6.10 to 6.60 (tiny tt, ${ }^{2} J_{\mathrm{HF}}=55.0 \mathrm{~Hz}$ , $\left.{ }^{3} \mathrm{~J}_{\mathrm{HH}}=4.6 \mathrm{~Hz}\right),-\mathrm{CH}_{2} \mathrm{CF}_{2}-\underline{\mathrm{H}}$ end-group originated from the transfer of proton to solvent or polymer or from backbiting. ${ }^{39}$

${ }^{31} \mathrm{P}$ NMR (162 MHz, DMSO- $d_{6}, \delta \mathrm{ppm}$ of P1, Figure S3): peak centred at $35.5 \mathrm{ppm}\left(-\underline{\mathrm{P}}(\mathrm{O})\left(\mathrm{OCH}_{3}\right)_{2}\right)$.

\section{Preparation of the solid polymer electrolytes (SPEs)}

SPEs were prepared by dissolving $100 \mathrm{mg}$ of copolymer and the required amount of LiTFSI (the dimethylphosphonate units: $\mathrm{Li}^{+}$ions molar ratio in the copolymers was fixed either to $2: 1,1: 1$, or $1: 2$ for each investigated copolymer) in $500 \mu \mathrm{L}$ of acetonitrile. Those solutions were casted into PTFE moulds and dried in the glove box to remove the majority of acetonitrile. Afterward, the samples were placed under vacuum for one week to totally remove the remaining of acetonitrile. Finally, the SPE film was obtained through a pressing machine. The SPE film was put on the first stainless steel, a second stainless steel was placed on top of the SPE film and this setup was assembled in a Swagelok cell for further impedance measurements. For the electrochemical stability tests, a second metallic lithium disk was placed on top of the SPE films. Finally, the SPE film was also detached from the first stainless steel disk to perform flammability tests by placing the films in the flame of a lighter for 5 seconds.

\section{Characterization}

\section{Nuclear magnetic resonance (NMR) spectroscopy}

${ }^{19} \mathrm{~F},{ }^{1} \mathrm{H}$, and ${ }^{31} \mathrm{P}$ NMR spectroscopies enabled to assess the composition of the copolymers. Recorded on a Bruker AC 400 Spectrometer $\left(376 \mathrm{MHz}\right.$ for ${ }^{19} \mathrm{~F}, 400 \mathrm{MHz}$ for ${ }^{1} \mathrm{H}$, and $162 \mathrm{MHz}$ for ${ }^{31} \mathrm{P}$ ), these techniques used DMSO- $d_{6}$ as the solvent Chemical shifts and coupling constants were given in parts per million (ppm) and Hertz ( $\mathrm{Hz})$, respectively.

\section{Size exclusion chromatography (SEC) measurements}

Molecular weights $\left(M_{n} s\right)$ and dispersities $(D s)$ of the poly(VDFco-VDMP) copolymers were determined from gel permeation (GPC) or size exclusion (SEC) chromatography with tripledetection GPC from Agilent Technologies using a PL03900605390 LC light scattering detector with two diffusion angles $\left(15^{\circ}\right.$ and $\left.90^{\circ}\right)$, a PL0390-06034 capillary viscometer, and a 390-
LC PL0390-0601 refractive index detector and two PL11136300 ResiPore $300 \times 7.5 \mathrm{~mm}$ columns. DMF (containing $0.1 \mathrm{wt}$ $\%$ of $\mathrm{LiCl}$ ) was used as the eluent at a flow rate of $0.8 \mathrm{~mL} \mathrm{~min}^{-1}$ and toluene as the flow rate marker. The entire SEC-HPLC system was thermostated at $35^{\circ} \mathrm{C}$. Poly(methyl methacrylate) standards enabled to calibrate the SEC instrument and the results were processed using the corresponding Agilent software.

\section{Thermogravimetric analysis (TGA)}

The thermogravimetric analysis of the precipitated and dried copolymers was achieved under air by means of a TGA 51 apparatus from TA Instruments from $23{ }^{\circ} \mathrm{C}$ to $580{ }^{\circ} \mathrm{C}$ at a heating rate of $10^{\circ} \mathrm{C} \mathrm{min}^{-1}$.

\section{Differential scanning calorimetry (DSC)}

DSC analyses of the copolymers were performed by means of a Netzsch DSC 200 F3 instrument under $\mathrm{N}_{2}$ atmosphere. The heating or cooling ranges were used from $-80^{\circ} \mathrm{C}$ to $200{ }^{\circ} \mathrm{C}$ at a scanning rate of $10{ }^{\circ} \mathrm{C} \mathrm{min}{ }^{-1}$. Melting points were assessed at the maximum of the enthalpy peaks, the area of which led to determine the melting enthalpy $\left(\Delta H_{m}\right)$. In addition, the degrees of crystallinity of the copolymers were calculated from equation 1 :

$$
\text { Degree of crystallinity }(\chi)=\frac{\Delta H_{m}}{\Delta H_{c}} \times 100
$$

where $\Delta H_{c}\left(104.5 \mathrm{~J} \mathrm{~g}^{-1}\right)$ corresponds to the enthalpy of melting of a $100 \%$ crystalline PVDF ${ }^{40,41}$ while $\Delta H_{m}$ stands for the heat of fusion of the copolymer (determined by DSC in $\mathrm{J} \mathrm{g}^{-1}$ ), respectively.

\section{Scanning electron microscopy (SEM)}

Scanning electron microscope (SEM) images were obtained in a SEM JEOL 7600F directly of the SPEs film.

\section{Ionic conductivity measurements}

Ionic conductivities were measured by electrochemical impedance spectroscopy (EIS) with a Biologic VMP300 apparatus. The SPE films were sandwiched between two stainless steel disks and inserted into Swagelok cells. The temperature dependence measurements were carried out from $100{ }^{\circ} \mathrm{C}$ to $30^{\circ} \mathrm{C}$ by gradually decreasing the temperature by steps of $10{ }^{\circ} \mathrm{C}$ with an equilibration time of $1 \mathrm{~h}$ between each step. The electrochemical response of the electrolytes was determined at different temperatures in the $7 \mathrm{MHz}-1 \mathrm{mHz}$ frequency range with an $\mathrm{AC}$ excitation voltage at $10 \mathrm{mV}$. At the end of the measurements, the Swagelok cell was opened in the glove box and the thickness of the SPE film was assessed.

\section{Electrochemical stability}

The electrochemical stability was determined on a Biologic VMP300 apparatus by linear sweep voltammetry. The SPE film was sandwiched between a stainless-steel working electrode and a lithium foil as counter and reference electrode. The Swagelok cell was assembled in a glovebox under argon and 
voltage was swept from $0 \mathrm{~V}$ to $5.5 \mathrm{~V}$ vs $\mathrm{Li} / \mathrm{Li}^{+}$at a scan rate of 1 $\mathrm{mV} / \mathrm{s}$.

\section{Results and discussion}

Poly(VDF-co-VDMP) copolymers were synthesized by radical copolymerization of vinylidene fluoride (VDF) with vinyl dimethylphosphonate (VDMP), initiated by a peroxide, named 2,5-dimethyl-2,5-di(tert-butylperoxy) hexane (DTBPH) at 115 ${ }^{\circ} \mathrm{C}$ in dimethyl carbonate (DMC), a green solvent ${ }^{42}$ that swells VDF well ${ }^{43-45}$ (Scheme 1).

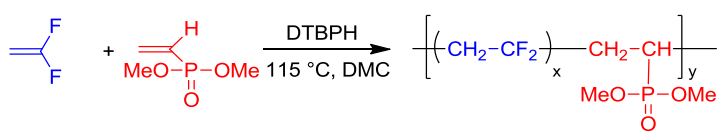

Scheme 1. Radical copolymerization of vinyl dimethylphosphonate (VDMP) with vinylidene fluoride (VDF) initiated by 2,5-di(tert-butylperoxy) hexane (DTBPH) in dimethyl carbonate (DMC).

Due to the gaseous nature of VDF, all copolymerizations were performed in high pressure autoclave. The experimental procedures, results and analyses of the obtained poly(VDF-coVDMP) copolymers (P1-P3) are listed in Table 1. During the runs of the reactions, the VDF consumption induced a drop of pressure (ca. 25 bars) in the reactor and, to some extent, confirmed the completion of the reaction. It is worth noting that under similar reaction conditions, the homopolymerization of VDMP failed under similar reaction conditions (Table 1).

For all experiments, the resulting random poly(VDF-co-VDMP) copolymers were produced in high yields (ca. 80\%). The physical nature of the obtained copolymers gradually changed from white solid powder to colorless viscous wax as the content of VDMP increased from $10 \%$ to $50 \%$ in the copolymer. These copolymers were characterized by ${ }^{1} \mathrm{H},{ }^{19} \mathrm{~F}$, and ${ }^{31} \mathrm{P}$ NMR spectroscopies (the spectra are in Figures S1-S3) and more details are provided in the electronic supporting information section. Actually, the key features are as follows. The ${ }^{1} \mathrm{H}$ NMR spectra (Figure S1) display the absence of any ethylenic protons that evidences the reactivity of VDMP monomer and the following features :i) at ca. $1.8 \mathrm{ppm}$ for $\mathrm{CH}$ group in VDMP $\left(-\mathrm{CH}_{2} \mathrm{CH}-\mathrm{PO}\left(\mathrm{OCH}_{3}\right)_{2}\right)$, ii) at ca. $2.3 \mathrm{ppm}$ assigned to reverse (tail-to-tail) addition in VDF-VDF dyad $\left(-\mathrm{CF}_{2} \mathrm{CH}_{2}-\mathrm{CH}_{2} \mathrm{CF}_{2}-\right)^{39,43-48}$ (iii) a broad signal in the 2.60-3.20 ppm range characteristic of the head-to-tail addition in VDFVDF dyad $\left(-\mathrm{CH}_{2} \mathrm{CF}_{2}-\mathrm{CH}_{2} \mathrm{CF}_{2}-\right.$ ), (iv) a signal at $2.80 \mathrm{ppm}$ assigned to the VDF-VDMP dyad $\left(-\mathrm{CH}_{2} \mathrm{CF}_{2}-\mathrm{CH}_{2} \mathrm{CH}\left[\mathrm{P}(\mathrm{O})\left(\mathrm{OCH}_{3}\right)_{2}\right]\right.$, and $(\mathrm{v})$ at $3.6 \mathrm{ppm}$ attributed to the $-\mathrm{OCH}_{3}$ in phosphonate moieties. The ${ }^{19} \mathrm{~F}$ NMR spectrum (Figure S2) highlights the expected signals of VDF units (i) at ca. -92 ppm attributed to the normal VDF-VDF dyads $\left(-\mathrm{CH}_{2} \mathrm{CF}_{2}-\mathrm{CH}_{2} \mathrm{C}_{2}-\right)$ in PVDF chains; ${ }^{49-51}$ (ii) at $-94.7 \mathrm{ppm}$ assigned to the fluorine atoms in $-\mathrm{CF}_{2}$ groups of VDF in VDFVDMP alternating dyads, ${ }^{23,24,49-51}$ (iii) at -114.0 and -116.2 ppm characteristic of the reverse or $\mathrm{H}-\mathrm{H}$ VDF-VDF dyads $\left(-\mathrm{CH}_{2} \mathrm{CF}_{2}-\mathrm{CF}_{2} \mathrm{CH}_{2}-\right) .{ }^{43-48}$ The characteristic signal centred at 36 $\mathrm{ppm}$ in the ${ }^{31} \mathrm{P}$ NMR spectrum (Figure S3) ) evidences the absence of any phosphorus atom adjacent to the double bond (expected at $18 \mathrm{ppm}$ ) that evidences the reactivity of VDMP monomer and the presence of dimethyl phosphonate group. ${ }^{23-}$ 24

The VDF contents in the copolymers was calculated via ${ }^{1} \mathrm{H}$ NMR spectroscopy, from equation 2:

$$
\begin{aligned}
& \text { mol\% VDF in copolymers }\left(\text { by }{ }^{1} H N M R\right) \\
& \qquad=\frac{\left(\int_{2.3}^{2.5} I_{1}+\int_{2.8}^{3.2} I_{2}\right) / 2-\int_{3.5}^{3.6} I_{3} / 6}{\left(\int_{2.3}^{2.5} I_{1}+\int_{2.8}^{3.2} I_{2}\right) / 2} \times 100 \text { (2) }
\end{aligned}
$$

Indeed, for the P3 copolymer, since the ${ }^{1} \mathrm{H}$ NMR signals assigned to $\mathrm{CH}_{3}$ in VDMP centred at $3.6 \mathrm{ppm}$ overlap with those of the residual solvent trapped in this highly viscous (wax) copolymer, the real VDF content in this product could not be calculated. Because of the lack of poly(VDF-co-VDMP) copolymer standards, the size exclusion chromatograms (SECs) indicate apparent molar masses $\left(M_{\mathrm{n}} \mathrm{s}\right)$ for the copolymers varying between 960 and $5,200 \mathrm{~g} \mathrm{~mol}^{-1}$ (Table 1) while dispersities ( $Đ s)$ are in the 1.39 to 1.67 range. The low molar masses of P2 and P3 probably originates from the high VDMP concentration that induced some transfer.

\section{Thermal properties of poly(VDF-co-VDMP) copolymers.}

The thermal stabilities of P1-P3 poly(VDF-co-VDMP) copolymers were determined by thermogravimetric analysis (TGA) under air (Figure 1). As expected, the thermal stability of the poly(VDF-co-VDMP) copolymers increased with the increase of the VDF content in the copolymer from P1 $(85$ mol\% VDF) to P3 (ca. 35-45 mol\% VDF), as highlighted by the $T_{d, 10 \%}$ (temperature for a $10 \%$ weight loss, Table 1 ). Copolymer P3 displays an initial loss (9\%) when the sample is heated under air just above $150{ }^{\circ} \mathrm{C}$ due to the evaporation of the trapped solvent or low molar mass oligomers. For all copolymers, a major weight loss is noted at $230-300{ }^{\circ} \mathrm{C}$ assigned to the decomposition of the copolymer backbone. The glass transition $\left(T_{\mathrm{g}}\right)$ and melting $\left(T_{m}\right)$ temperatures as well as the crystallinity of the copolymers (using equation (1)) were determined by differential scanning calorimetry (DSC) analysis (Table 1). ${ }^{48}$ Only one $T_{\mathrm{g}}$ was observed for each studied copolymer (Figure 2, left) confirming their statistical nature. The $T_{\mathrm{g}} \mathrm{s}$ increased after LiTFSI was mixed into the copolymer, because of the decreasing of the chain mobility and dynamics of the system when the salt is added ${ }^{52}$ (see Figure 2, right). Moreover, those $T_{\mathrm{g}}$ values, around room temperature (Figure $2)$, are an interesting feature to obtain good ionic conductivities for SPEs since the ion conduction mechanism in solid polymer electrolytes is generally attributed to polymer segment motion. As expected, only P1 and P2 copolymers exhibited melting temperatures while the highly viscous $\mathrm{P} 3$ copolymer did not. This is due to the high VDMP amount in the 
copolymer that affects the highly crystalline PVDF domains thus changing the morphology of the solid polymer into highly viscous liquid one. Such a behavior is similar as that of poly(VDF-co-hexafluoropropylene) copolymers for which a HFP molar percentage higher than $18 \%$ leads to amorphous materials. ${ }^{53}$ The degree of crystallinity $(x)$ increased from 9 to $24 \%$ with an increase of VDF mol\% in the copolymer from P2 (59 mol\%) to P1 (84 mol\%). The degree of crystallinity of VDF units was not affected by the addition of LiTFSI in the SPEs.

Table 1. Experimental conditions and results (molar masses, dispersities, and thermal properties) of the radical copolymerisation of VDF with VDMP.

\begin{tabular}{|c|c|c|c|c|c|c|c|c|c|c|c|}
\hline \multirow[t]{2}{*}{ entry } & \multicolumn{2}{|c|}{ VDF mol\% } & \multirow{2}{*}{$\begin{array}{l}P_{\max }{ }^{c} \\
\text { (bar) }\end{array}$} & \multirow{2}{*}{$\begin{array}{l}\Delta P^{d} \\
\text { (bar) }\end{array}$} & \multirow[t]{2}{*}{ yield (\%) } & \multirow{2}{*}{$M_{n, S E C}^{e}$} & \multirow[t]{2}{*}{$\theta^{e}$} & \multirow{2}{*}{$\begin{array}{l}T_{d 10 \%}^{f} \\
\left({ }^{\circ} \mathrm{C}\right)\end{array}$} & \multirow{2}{*}{$\begin{array}{l}T_{m}{ }^{g} \\
\left({ }^{\circ} \mathrm{C}\right)\end{array}$} & \multirow{2}{*}{$\begin{array}{l}T_{g}^{g} \\
\left({ }^{\circ} \mathrm{C}\right)\end{array}$} & \multirow[t]{2}{*}{$\left.\chi^{g} \quad i^{\%}\right)$} \\
\hline & feed & copolymer $^{\mathrm{b}}$ & & & & & & & & & \\
\hline P0 & 0 & 0 & - & - & 0 & - & - & - & - & & - \\
\hline P1 & 90 & 84 & 33 & 24 & 80 & 5200 & 1.67 & 300 & 126 & -17 & 23 \\
\hline P2 & 70 & 59 & 32 & 28 & 81 & 990 & 1.39 & 290 & 48 & -10 & 9 \\
\hline P3 & 50 & n.d & 35 & 27 & 79 & 970 & 1.61 & 240 & none & 0 & none \\
\hline
\end{tabular}

${ }^{\mathrm{a}}$ Conditions: initiator $=1 \mathrm{~mol} \%$ with respect to total monomers; solvent used $=30 \mathrm{~mL}$; ${ }^{\mathrm{b}}$ Copolymer compositions were determined by ${ }^{1} \mathrm{H}$ NMR spectroscopy from eq. (2); ${ }^{\mathrm{C}} \mathrm{P}_{\text {max }}$ : maximum pressure during the polymerization; ${ }^{\mathrm{d}} \Delta \mathrm{P}$ : pressure drop noted in the vessel between maximum pressure and pressure at the end of the polymerization. ${ }^{\mathrm{e}} M_{\mathrm{n}} \mathrm{s}$ and $\emptyset s$ were assessed by SEC in DMF using poly(methyl methacrylate) standards. ${ }^{\mathrm{f}}$ Temperature for a $10 \%$ wt loss determined by $\mathrm{TGA}$ under air; $10{ }^{\circ} \mathrm{C} / \mathrm{min}$. ${ }^{\mathrm{g}}$ Determined by DSC; $\chi$ : crystallinity assessed from equation 1.

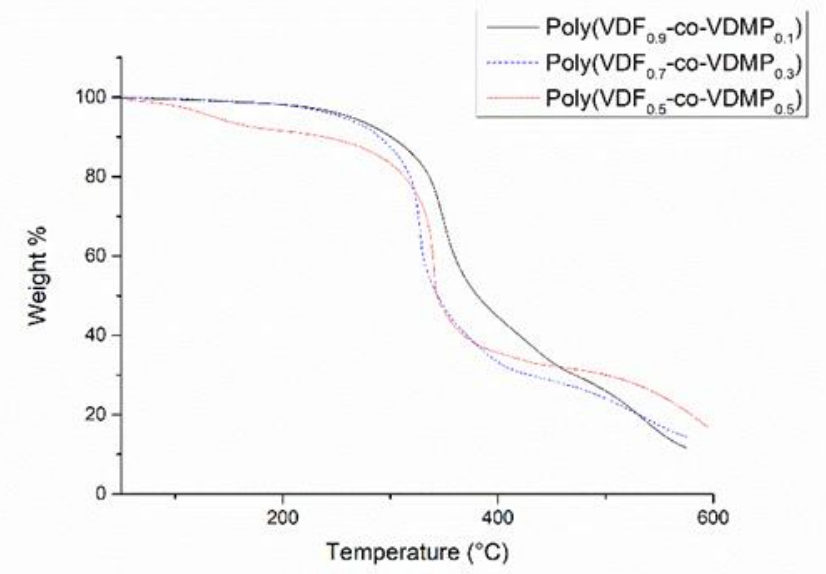

Figure 1. TGA thermograms of poly(VDF-co-VDMP) copolymers (P1-P3, Table 1), heated at $10^{\circ} \mathrm{C} \mathrm{min}^{-1}$ under air.
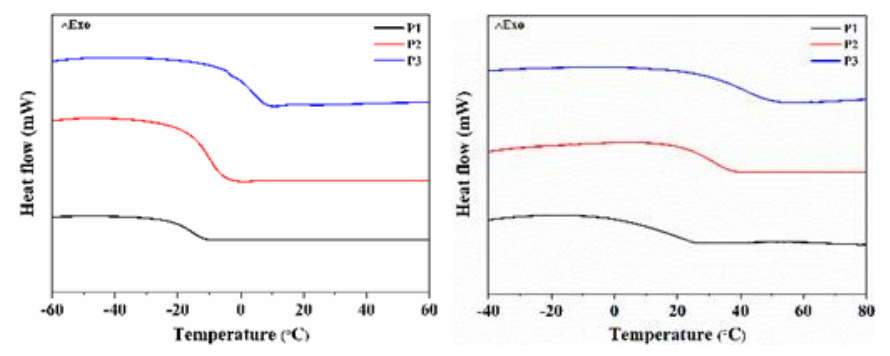

This journal is (C) The Royal Society of Chemistry 20xx
Figure 2. Left: DSC traces of poly(VDF-co-VDMP) copolymers (P1-P3, Table1) focusing on $T_{\mathrm{g}}$ s. Right: DSC traces of poly(VDFco-VDMP) SPEs focusing on $T_{\mathrm{gs}}$ (the molar ratio of dimethylphosphonate units to $\mathrm{Li}^{+}$ions fixed to $2: 1$.

\section{Ionic conductivity of poly(VDF-co-VDMP)/LiTFSI solid polymer electrolytes}

Electrochemical impedance spectroscopy (EIS) was conducted on solid polymer electrolytes (SPES) obtained from the three studied poly(VDF-co-VDMP) copolymers added with LiTFSI as the lithium salt. SPEs were prepared by casting from an acetonitrile solution of the poly(VDF-Co-VDMP)/LiTFSI mixture in a PTFE mould. The VDMP/LiTFSI molar ratio was fixed to three values: 2:1, 1:1 and 1:2. After extensive drying and pressing of the obtained SPEs films with a thickness of $300 \mu \mathrm{m}$, stainless steel disks were deposited on both sides of the films and the whole assembly was introduced into a Swagelok cell for further EIS measurements. The resulting films were observed by SEM in order to visualize the eventual presence of LiTFSI crystalline domains (Figure 3 ). Indeed, no aggregated domains were observed in P1 with VDMP/LiTFSI at 2:1, while some aggregation was noted in P2 with VDMP/LiTFSI at 2:1, and large aggregated domains were visualized in P3 with VDMP/LiTFSI at 2:1 (Figure 3). 

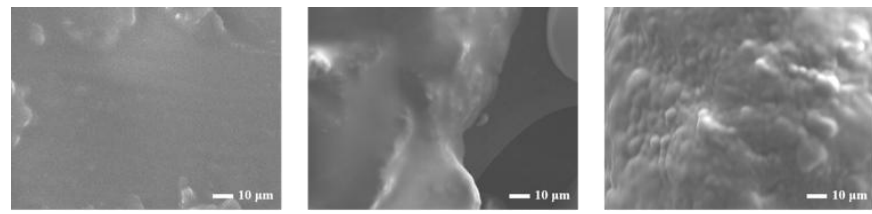

Figure 3. SEM images of SPEs prepared from P1 (left), P2 (middle) and P3 (right) poly(VDF-co-VDMP) copolymers containing LiTFSI at VDMP/ $\mathrm{Li}^{+}$in 2:1 molar ratio.

Quantitative information about ionic conductivity, $\sigma$, can be derived from the bulk resistance determined by EIS, R, the thickness, $d$, and the surface area, $S$, of the SPE via the equation 3:

$$
\sigma=\frac{1}{R} \times \frac{d}{S}
$$

The ionic conductivities for the SPEs prepared from the P1-P3 poly(VDF-co-VDMP) copolymers loaded with different LiTFSI amounts have been determined at different temperatures (Figure 4 and Table S1). The measured ionic conductivities were in the same range whatever the used copolymer (P1, P2 or P3) and the VDMP/LiTFSI molar ratio. No clear trend could be established concerning the influence of the VDMP/LiTFSI molar ratio. However, it can be concluded that the composition of the copolymer has a slight effect on the ionic conductivity values, the values obtained for the P1/LiTFSI SPES being the best ones while the P3/LiTFSI SPEs give the worst values (Table S1). Those results could be considered surprising at a first glance since the P3/LiTFSI SPEs are amorphous (see Table 1), contain the highest amount of VDMP units and thus the highest LiTFSI amount. So, those samples should in principle lead to the better ionic conductivity values. However, the large LiTFSI amount present in those samples leads to the formation of poorly ion conducting LiTFSI aggregates as evidenced by SEM (Figure 3) and in turn to decreased ionic conductivity values for the SPEs. In contrast, P1/LiTFSI SPEs contain lowest VDMP amount (and thus lowest LiTFSI amounts) and display a crystallinity degree of $23 \%$ for its PVDF moeities (Table 1). Despite those characteristics, the ionic conductivity values of the P1/LiTFSI SPEs are always superior to the ones measured for the P3/LiTFSI SPEs. In addition, no aggregated LiTFSI domains have been detected in the P1/LiTFSI SPEs. Some aggregated LiTFSI domains have been observed for the P2/LiTFSI SPEs which contain an intermediate VDMP amount (and thus of LiTFSI). This could explain why the ionic conductivities of the P2/LiTFSI SPEs are a bit lower than those of the P1/LiTFSI SPES.

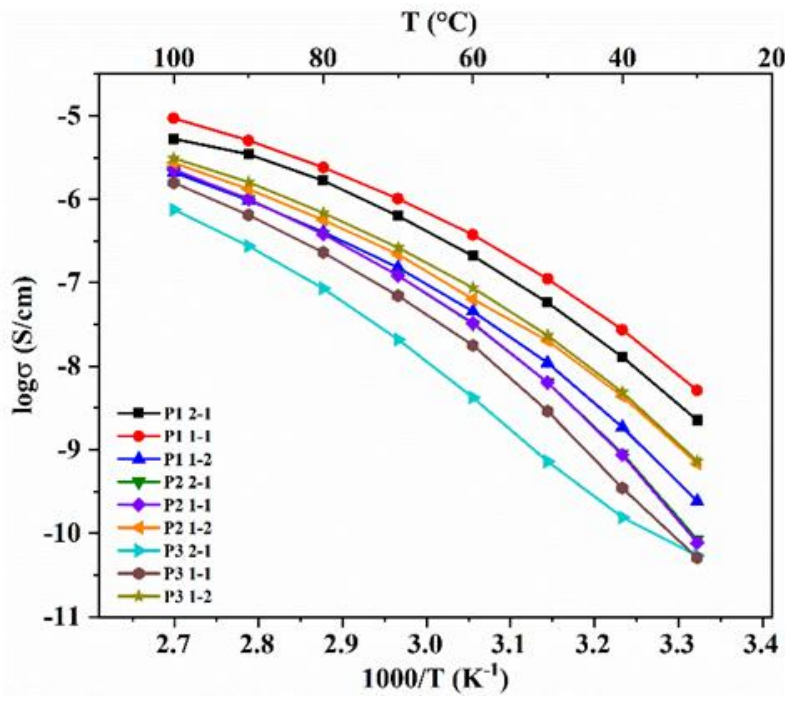

Figure 4. Ionic conductivities measured at different temperatures for the three investigated poly(VDF-co-VDMP) copolymers added with LiTFSI with VDMP/Li ${ }^{+}$2:1, 1:1 and 1:2 molar ratios.

It is worth noting that the data plotted in Figure 4 show three parallel quasi-linear evolutions of the ionic conductivity as a function of temperature for the three investigated copolymers. This observation suggests that the mechanism of ionic conduction follows the well-known Vogel-FulcherTammann (VFT) model which generally occurs for SPEs above their glass transition, as shown in Figure 5 in which the VFT model has been successfully applied for the studied samples and revealed straight lines. ${ }^{54}$

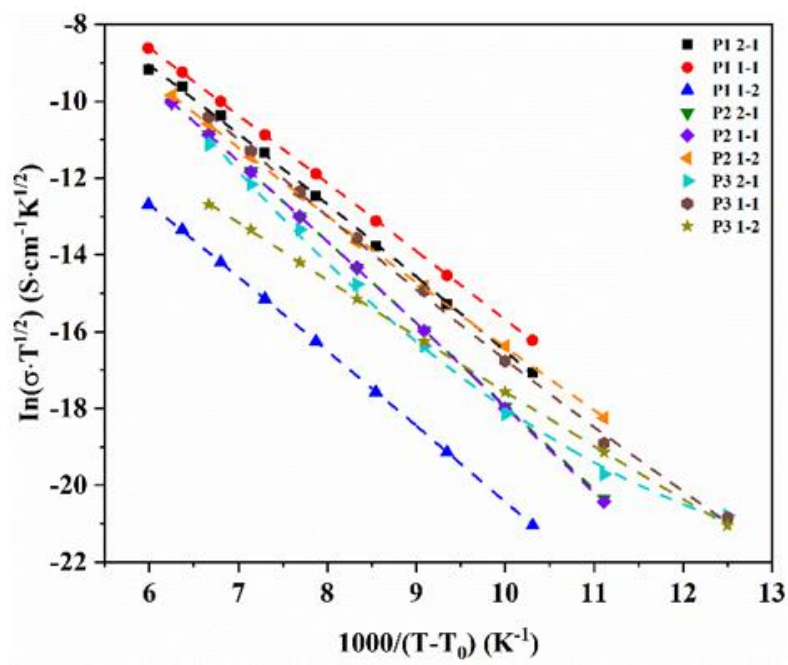

Figure 5. Temperature dependence of the ionic conductivity for the investigated SPEs using the VFT model.

\section{Electrochemical stability}

The electrochemical stability window of the investigated SPEs has been evaluated by linear sweep voltammetry between $0 \mathrm{~V}$ and $5.5 \mathrm{~V} \mathrm{vs} \mathrm{Li} / \mathrm{Li}^{+}$at a scan rate of $1 \mathrm{mV} / \mathrm{s}$ (Figure 6). For these experiments, the SPE films deposited on a stainless-steel disk 
have been covered by a lithium foil. The SPEs appear to be electrochemically stable in a wide range of potentials varying from 0 to $4.7 \mathrm{~V}$ vs Li/Li ${ }^{+}$. Degradation is observed above $5.0 \mathrm{~V}$ and might be attributed to the oxidation corrosion of stainlesssteel working electrode. These data confirm the high chemical and electrochemical stability related to the presence of fluorinated groups in our copolymers.

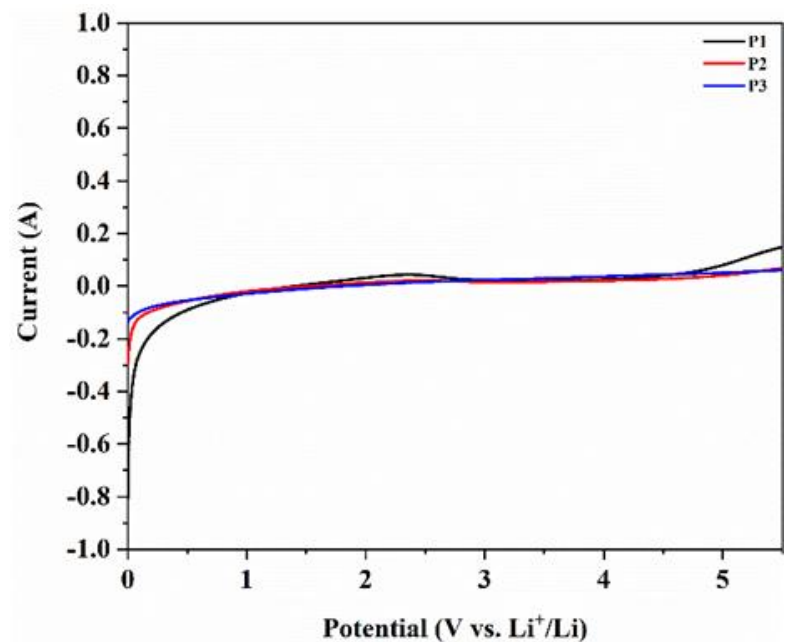

Figure 6. Linear sweep voltammetry performed on the SPES prepared from $\mathrm{P} 1, \mathrm{P} 2$ and $\mathrm{P} 3$ with $\mathrm{VDMP} / \mathrm{Li}^{+}$2:1 molar ratio at a scan rate of $1 \mathrm{mV} / \mathrm{s}$.

\section{Flammability tests}

Phosphonate groups are well known to act as fire-retardants and low molar mass phosphonate compounds are often added as additives in commercial battery electrolytes based on organic solvents. ${ }^{28}$ Polymers containing phosphonate groups have also demonstrated fire-retardant abilities. ${ }^{26}$ Therefore, phosphonate groups in the studied poly(VDF-co-VDMP) copolymers are expected to afford interesting fire-resistance properties. In preliminary experiments, we have submitted P1P3 poly(VDF-co-VDMP) SPEs films (with VDMP/Li ${ }^{+}$2:1 molar ratio) to the flame of a lighter (Figure 7). After 5 seconds, the samples have been withdrawn from the flame. For the pictures shown in Figure 7, it can be observed that all the three samples do not burn, do keep their white color while no char is observed. The samples derived from $\mathrm{P} 1$ and $\mathrm{P} 2$ are maintaining their shape while the sample containing P3 is flowing (see picture in the bottom right in Figure 7). This observation can be related to the presence of crystalline domains in P1 and P2 helping the films to keep their integrity even when they are heated in a flame for a few seconds. In contrast, P3 is an amorphous polymer and, when heated in the flame of the lighter, is transformed into a flowing viscous fluid.
P1
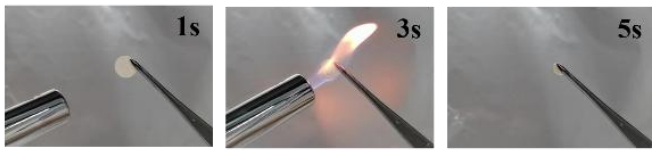

P2
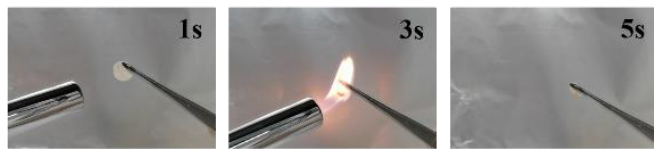

P3
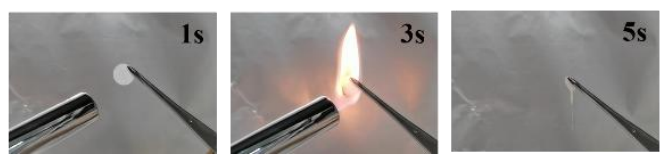

Figure 7. Flammability tests performed on the SPEs films derived from $\mathrm{P} 1, \mathrm{P} 2$ and $\mathrm{P} 3$ copolymers with $\mathrm{VDMP} / \mathrm{Li}^{+}$2:1 molar ratio versus time

\section{Conclusions}

For the first time, solid polymer electrolytes have been prepared from poly(VDF-co-VDMP) statistical copolymers. Although the measured ionic conductivities are remaining low even at elevated temperature $\left(100{ }^{\circ} \mathrm{C}\right)$, the obtained electrolytes display very interesting features calling for further investigations of solid polymer electrolytes incorporating either fluorinated or phosphonate moieties. On one hand, fluorinated groups are affording outstanding thermal, (electro) chemical stabilities and mechanical integrity thanks their crystalline domains to the electrolytes. On the other hand, phosphonate groups are allowing exceptional fire-resistance for the electrolytes. Further investigation will concentrate on the understanding of the ion-conduction mechanism and how the ionic conductivity can be increased for such systems.

\section{Conflicts of interest}

There are no conflicts to declare.

\section{Acknowledgements}

LB is grateful to the Chinese Scholarship Council (CSC) and to the UCLouvain-CSC co-fund for a PhD grant. GD is grateful to INNOVIRIS for a DOCTIRIS PhD grant. In addition, financial supports from the "UM-AUF-CNRSL grant" (University of Montpellier (UM), the Agence Universitaire de la Francophonie (AUF), and the National Council for Scientific Research in Lebanon (CNRS-L)) are greatly appreciated for MW's grants. BA also thanks the French Fluorine Network (GIS).

\section{Notes and references}

1 M. Li, J. Lu, Z. Chen and K. Amine, Adv. Mater., 2018, 30, 1800561.

2 G. Zubi, R. Dufo-López, M. Carvalho and G. Pasaoglu, Renew. Sust. Energ. Rev., 2018, 89, 292-308.

3 G. Berckmans, M. Messagie, J. Smekens, N. Omar, L. Vanhaverbeke, J. Van Mierlo, Energies, 2017, 10, 1314. 
4 A. Yoshino: Development of the Lithium-Ion Battery and Recent Technological Trends. In Lithium-Ion Batteries, G. Pistoia, Ed., Elsevier: Amsterdam, 2014, pp 1-20.

5 J. Y. Song, Y. Y. Wang and C. C. Wan, J. Power Sources, 1999 77, 183-197.

6 Z. Xue, D. He, and X. Xie, J. Mater. Chem. A, 2015, 3, 1921819253.

7 P. Carol, P. Ramakrishnan, B. John, and G. Cheruvally, J. Power Sources, 2011, 196, 10156-10162.

8 Y. H. Liao, D. Y. Zhou, M. M. Rao, W. S. Li, Z. P. Cai, Y. Liang and C. L. Tan, J. Power Sources, 2009, 189, 139-144.

9 J. Liu, W. Li, X. Zuo, S. Liu and Z. Li, J. Power Sources, 2013, 226, 101-106.

10 J. Mindemark, M. J. Lacy, T. Bowden and D. Brandell, Prog. Polym. Sci., 2018, 81, 1-30.

11 Z. Cui, E. Drioli, Y. M. Lee, Prog. Polym. Sci., 2013, 39, 164198.

12 D. Smith, S. lacono and S. S. Iyer: Handbook of Fluoropolymer Science and Technology, Wiley: New York, 2014.

13 B. Ameduri and H. Sawada: Fluorinated Polymers : Volume 2: Applications, RSC: Oxford, 2016, Vol. 2.

14 T. Soulestin, V. Ladmiral, F. D. Dos Santos and B. Ameduri, Prog. Polym. Sci., 2017, 72, 16-60.

15 C. M. Costa, M. M. Silva and S. Lanceros-Méndez, RSC Adv., 2013, 3, 11404-11417

16 M. Zhao, X. Zuo, C. Wang, X. Xiao, J. Liu and J. Nan, lonics, 2016, 22, 2123-2132.

17 A. M. Stephan and D. Teeters, J. Power Sources, 2003, 119121, 460-464.

18 H. Xie, Z. Tang, Z. Li, Y. He, Y. Liu and H. Wang, J. Solid State Electrochem, 2008, 12, 1497-1502.

19 G. Chen, F. Zhang, Z. Zhou, J. Li and Y. Tang, Adv. Energy Mater., 2018, 8, 1801219.

20 A. Alaaeddine, J. Vergnaud, J. Rolland, A. Vlad, J.-F. Gohy and B. Ameduri, Polym. Chem., 2015, 6, 6021-6028.

21 M. Wehbi, G. Dolphijn, J. Brassinne, J.-F. Gohy and B. Ameduri, Macromolecules, 2019, 52, 3056-3065.

22 F. Boujioui, F. Zhuge, H. Damerow, M. Wehbi, B. Améduri, J.F. Gohy, J. Mater. Chem. A, 2018, 6, 8514-8522.

23 M. Wehbi, D. Bourgeois and B. Améduri, Polym Chem., 2019, 10, 4173-4184.

24 M. Wehbi, A. Mehdi, A. Alaaeddine, N. Jaber and B. Améduri, Polymers, 2020, 12, 1955.

25 S. Maiti, S. Banerjee and S. K. Palit, Prog. Polym. Sci., 1993, 18, 227-261.

26 S. Monge and G. David: Phosphorus-Based Polymers: From Synthesis to Applications, The Royal Society of Chemistry: Cambridge, 2014, 318 pp.

27 S. Banerjee, M. Wehbi, A. Manseri, A. Mehdi, A. Alaaeddine, A. Hachem and B. Ameduri, ACS Appl. Mater. Interface, 2017, 9, 6433-6443.

28 R. Sonnier, L. Ferry and J.-M. Lopez-Cuesta: Flame Retardancy of Phosphorus-Containing Polymers, In Phosphorus-Based Polymers: From Synthesis to Applications, S. Monge, G. David, Eds., The Royal Society of Chemistry: Oxford, 2014, pp 252-270.

29 M. Yamabe, K. Akiyama, Y. Akatsuka and M. Kato, Eur. Polym. J., 2000, 36, 1035-1041.

30 A. L. Rusanov, P. V. Kostoglodov, M. J. M. Abadie, V. Y. Voytekunas and D. Y. Likhachev: Proton-Conducting Polymers and Membranes Carrying Phosphonic Acid Groups, In Fuel Cells II, G. G. Scherer, Ed., Springer Berlin Heidelberg: Berlin, Heidelberg, 2008, pp 125-155.

31 I. Dimitrov, S. Takamuku, K. Jankova, P. Jannasch and S. Hvilsted, Macromol. Rapid Commun., 2012, 33, 1368-1374.

32 B. Lafitte and P. Jannasch, On the Prospects for Phosphonated Polymers as Proton-Exchange Fuel Cell
Membranes, In Advances in Fuel Cells, T. S. Zhao, K. D. Kreuer and T. Van Nguyen, Eds., Elsevier: Oxford, 2007, pp 119-185.

33 R. Tayouo, G. David, B. Ameduri, J. Roziere and S. Roualdes, Macromolecules, 2010, 43, 5269-5276.

34 Y. Catel, V. Besse, A. Zulauf, D. Marchat, E. Pfund, T.-N. Pham, D. Bernache-Assolant, M. Degrange, T. Lequeux, P. J. Madec and L. Le Pluart, Eur. Polym. J., 2012, 48, 318-330.

35 E. Matczak-Jon and V. Videnova-Adrabińska, Coord. Chem. Rev., 2005, 249, 2458-2488.

36 M. Wehbi, A. Mehdi, C. Negrell, G. David, A. Alaaeddine and B. Améduri, ACS Appl. Mater. Interfaces, 2020, 12, 38-59.

37 G. David, C. Negrell-Guirao, F. Iftene, B. Boutevin and K. Chougrani, Polym Chem., 2012, 3, 265-274.

38 M. Banks, J. R. Ebdon and M. Johnson, Polymer, 1994, 35 3470-3473.

39 M. Pianca, E. Barchiesi, G. Esposto and S. Radice, J. Fluor Chem., 1999, 95, 71-84.

40 K. Nakagawa and Y. Ishida, Kolloid-Z.Z. Polym., 1973, 251 103-107.

41 K. Nakagawa and Y. Ishida, J. Polym. Sci. Part B: Polym. Phys. 1973, 11, 2153-2171.

42 P. Tundo and M. Selva, Acc. Chem. Res., 2002, 35, 706-716.

43 A. D. Asandei, Chem. Rev., 2016, 116, 2244-2274.

44 A. D. Asandei, O. I. Adebolu and C. P. Simpson, J. Am. Chem. Soc., 2012, 134, 6080-6083.

45 A. D. Asandei, O. I. Adebolu, C. P. Simpson and J.-S. Kim, Angew. Chem. Int. Ed., 2013, 52, 10027-10030.

46 Y. Patil, A. Alaaeddine, T. Ono and B. Ameduri, Macromolecules, 2013, 46, 3092-3106.

47 C. P. Simpson, O. I. Adebolu, J.-S. Kim, V. Vasu and A. D. Asandei, Macromolecules, 2015, 48, 6404-6420.

48 E. B. Twum, C. Gao, X. Li, E. F. McCord, P. A. Fox, D. F. Lyons and P. L. Rinaldi, Macromolecules, 2012, 45, 5501-5512.

49 R. Souzy, B. Ameduri and B. Boutevin, Macromol. Chem. Phys., 2004, 205, 476-485.

50 C. Boyer and B. Ameduri, J. Polym. Sci., Part A: Polym. Chem., 2009, 47, 4710-4722.

51 Y. Patil and B. Ameduri, Polym. Chem., 2013, 4, 2783-2799.

52 W.-J. Liang, C.-L. Kuo, C.-L. Lin and P.-L. Kuo, J. Polym. Sci., Part A: Polym. Chem., 2002, 40, 1226-1235.

53 J.-M. Tarascon, A. S. Gozdz, C. Schmutz, F. Shokoohi and P. C. Warren, Solid State Ion., 1996, 86, 49-54.

54 X. Qian, N. Gu, Z. Cheng, X. Yang, E. Wang and S. Dong, J. Solid State Electrochem, 2001, 6, 8-15.

\section{TOC entry}

Solid polymer electrolytes with fire-retardant properties have been prepared from copolymers based on vinyl dimethyl phosphonate and vinylidene fluoride

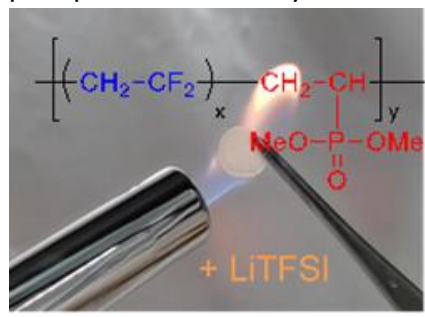

